\title{
Preliminary results in the immunodiagnosis of tuberculosis in children based on T cell responses to ESAT-6 and PPD antigens
}

\author{
Daniele SM Van-Lume, Joelma R de Souza, Wlademir G Melo, Victor L Melo', Marta ML Cabral', \\ Joakim C Rego², Haiana C Schindler, Frederico GC Abath ${ }^{\dagger}$, Silvia ML Montenegro/ ${ }^{+}$
}

Departamento de Imunologia, Centro de Pesquisas Aggeu Magalhães-Fiocruz, Av. Moares Rego s/n, Cidade Universitária, 50670-420 Recife, PE, Brasil ${ }^{1}$ Hospital das Clínicas, Universidade Federal de Pernambuco, Recife, PE, Brasil ${ }^{2}$ Ambulatório de Pediatria e Cardiologia Infantil, Instituto Materno Infantil Professor Fernando Figueira, Recife, PE, Brasil

The aim of this work was to study the difference in interferon gamma (IFN- $\gamma)$ production by $T$ lymphocytes after early secretory antigen target 6 (ESAT-6) or purified protein derivate (PPD) stimulation in whole blood culture supernatants from children with suspected tuberculosis $(T B)$ disease $(n=21)$, latent TB infection $(n=16)$ and negative controls $(\mathrm{NC})(n=22)$ from an endemic area in Brazil. The concentration of $I F N-\gamma(\mathrm{pg} / \mathrm{ml})$ was measured by enzyme linked immunosorbent assay and the differences in the IFN- $\gamma$ levels for each group were compared and evaluated using an unpaired Student's t-test; $p$ values $<0.05$ were considered significant. Measurement of IFN- $\gamma$ levels after ESAT-6 stimulation raised the possibility of early diagnosis in the latent TB group $(p=0.0030)$. Nevertheless, the same group showed similar responses to the NC group $(p>0.05)$ after PPD stimulation. The IFN- $\gamma$ assay using ESAT-6 as an antigenic stimulus has the potential to be used as a tool for the immunodiagnosis of early TB in children.

Key words: tuberculosis in children - immunodiagnosis - ELISA - ESAT-6 - PPD

Tuberculosis (TB) is a major global public health problem. The World Health Organization estimates that one-third of the world's population is infected with Mycobacterium tuberculosis, which is responsible for 8.7 million new TB cases and approximately 3 million deaths annually (Doherty et al. 2002, Vendramini et al. 2005). Around 116,000 new cases of TB are identified each year in Brazil, of which $10 \%$ are in children. Recently, there has been an increased interest in the field of TB diagnosis, especially in developing countries (Hijjar et al. 2001).

The gold standard for TB diagnosis is based on a combination of clinical and radiological examination, epidemiological investigation, appropriate response to antituberculosis therapy and microbiological testing (culture and baciloscopy). Diagnosis is particularly difficult in children because they are generally paucibacilar, thus decreasing the sensitivity of microbiological tests, establishing an asymptomatic infection. This asymptomatic and/or latent phase can persist for many years, with an approximately $10 \%$ risk of active disease reactivation (Jasmer et al. 2002, Tufariello et al. 2003). The tuberculin skin test (TST) using purified protein derivative (PPD) has been used to support the diagnosis of suspected TB disease and latent TB infection. However, the main drawback of the TST is the lack of specificity due to cross-reactivity with antigens present in other Mycobacterium species, such as

Financial Support: PDTIS-Fiocruz, Capes

+Corresponding author: silvia@cpqam.fiocruz.br

† In memoriam

Received: 3 December 2007

Accepted: 9 June 2008
M. bovis bacillus Calmette-Guerin (BCG) used for vaccination, and previous exposure to environmental nontuberculosis mycobacteria (Lein et al. 1999, ATS 2000b, Sant'Anna et al. 2002, Scarpellini et al. 2004). Thus, new strategies for specific tests to diagnose infection and TB disease in children are urgently needed to overcome the limitations of TST (Scarpellini et al. 2004, Kunst 2006, Teixeira et al. 2007).

Recently, in vitro studies with cattle and humans measuring interferon gamma (IFN- $\gamma$ ) -secreting T cells have shown that the use of the specific recombinant antigen early secretory antigen target - 6 (ESAT-6) in immunodiagnostic tests could be a potential diagnostic tool to detect active TB with a high specificity (Van Pinxteren et al. 2000, Munk et al. 2001, Pai et al. 2004, Weldingh et al. 2005, Teixeira et al. 2007). This protein is encoded within the region of difference 1 (RD1) of the M. tuberculosis genome and is more specific to this bacteria than PPD (Scarpellini et al. 2004, Goletti et al. 2005) due to its absence in all vaccine strains of BCG and all environmental isolates, except for Mycobacterium kansasii, Mycobacterium szulgai, Mycobacterium flavescens and Mycobacterium marinum (Ravn et al. 1999, Arend et al. 2002, Goletti et al. 2004, Scarpellini et al. 2004, Ravn et al. 2005). Therefore, the aim of this study was to investigate the difference in IFN- $\gamma$ production by whole blood T cells against the recombinant antigen ESAT- 6 and PPD in vitro in children from a Brazilian endemic area with suspected TB disease, with latent TB infection or without knowledge of previous contact with bacillary TB.

Children between the ages of 3 to 15 years who were BCG vaccinated 24-48 h after birth were selected according to the criteria used by the ATS (2000a). The children were enrolled into three groups: 1) patients with suspected pulmonary TB disease $(\mathrm{n}=21)$, composed of individuals who had an epidemiological history with 
bacillary TB contact, clinical evidence, chest radiography compatible with TB and a TST $>10 \mathrm{~mm}$. This group was followed-up during TB treatment to evaluate their clinical responses. In this group, two patients were diagnosed with extra-pulmonary TB that was confirmed by bone biopsy culture; 2) subjects with latent TB infection $(\mathrm{n}=16)$, including children who had a TST $>10 \mathrm{~mm}$ and had a history of contact with an adult who had active TB. These patients underwent isoniazid chemoprophylaxis therapy. Prior to treatment, both groups 1 and 2 were selected from the Hospital das Clínicas, Recife-PE and the Instituto Materno Infantil Professor Fernando Figueira (IMIP); 3) negative control (NC) group $(\mathrm{n}=22)$ that was composed of children with a negative TST reaction who were without a history of contact with bacillary TB patients and who were without specific signs and symptoms of TB. This group was selected from the IMIP cardiologic infirmary. The mean ages, the TST results for each group and the gender percentage for this study are shown in Table. Individuals diagnosed with Human Immunodeficiency Virus, autoimmune diseases, rheumatic cardiopathies or who had taken immune suppressive drugs in the three months before enrollment were excluded from this study. The study protocol was approved by the Ethical Committee of both the Centro de Pesquisas Aggeu Magalhães-Fiocruz and by the IMIP. Informed consent was obtained from the parents or legal representatives of participating minors. All the adult representatives answered a questionnaire about contact with patients known to have TB or risk groups for such an infection.

Blood samples $(3 \mathrm{ml})$ were taken with heparin $(10 \mathrm{U} / \mathrm{ml})$ by venipuncture. The whole blood was cultivated in RPMI 1640 medium with penicillin and streptomycin $(100 \mathrm{U} / \mathrm{ml}, 100 \mu \mathrm{g} / \mathrm{ml})$, and incubated with ESAT-6 (3 $\mu \mathrm{g} / \mathrm{ml})$, PPD $(5 \mu \mathrm{g} / \mathrm{ml})$ or PMA/Iono (Phorbol Miristate Acetate, $5 \mu \mathrm{g} / \mathrm{ml}$; Ionomicin, $1 \mu \mathrm{g} / \mathrm{ml}$ ) at $37^{\circ} \mathrm{C}$ in a humidified $\mathrm{CO}_{2}$ atmosphere for $120 \mathrm{~h}$. Supernatants were harvested and immediately frozen at $-70^{\circ} \mathrm{C}$ until analysis. The concentration of IFN- $\gamma$ produced by T cells in response to antigen (ESAT- 6 or PPD) or mitogen (PMA/Iono) stimulation in duplicate samples was determined by the Quantikine kit (R\&D Systems) enzymelinked immunosorbent assay, as described in the manufacturer's instructions. The results of these analysis were expressed as $\mathrm{pg} / \mathrm{ml}$. ESAT- 6 and PPD were obtained from Statens Serum Institute (Copenhagen, Denmark) by donation and through commercial means, respectively. The differences in IFN- $\gamma$ levels from each group were compared and evaluated by an unpaired Student's $t$ test; $\mathrm{p}$ values of $<0.05$ were considered significant.

ThesuspectedTBdiseasegroup $($ mean $=901.682 \mathrm{pg} / \mathrm{ml})$ and the NC group (mean $=136.772 \mathrm{pg} / \mathrm{ml}$ ) differed significantly with respect to the levels of IFN- $\gamma$ produced in response to ESAT-6 antigen stimulation $(p=0.0025)$. Also, a significant difference was observed in the cytokine levels for the TB-infected group (mean $=874.384 \mathrm{pg} / \mathrm{ml})$ and the NC group $(\mathrm{p}=0.0030 ;$ Fig. A). The ESAT- 6 antigen is a major target molecule for the memory $\mathrm{T}$ cell response and a possible antigen candidate for future vaccines (Harboe et al. 1996). Thus, analysis of IFN- $\gamma$ levels in response to ESAT- 6 antigen stimulation may be an important tool in immunodiagnostic assays to detect latent TB infection in children.

In humans, PPD is a highly sensitive reagent for the in vivo skin test and as an antigen for in vitro stimulation studies (Connell et al. 2006). In this work, statistical differences were shown between the $\mathrm{NC}$ group (mean = $522.498 \mathrm{pg} / \mathrm{ml}$ ) and the suspected TB disease group (mean $=1273.770 \mathrm{pg} / \mathrm{ml} ; \mathrm{p}=0.0321)$ when PPD was used as in vitro stimulus. Moreover, IFN- $\gamma$ levels were increased in the NC group after stimulation with this antigen compared to stimulation with ESAT-6. This difference is due to the fact that PPD contains a large number of antigens shared among many different mycobacterial strains (Aggerbeck \& Madsen 2006). This characteristic of PPD contributes to a decreased specificity in activating $\mathrm{T}$ cells from populations of patients who are sensitized to mycobacterial antigens as a consequence of BCG vaccination and/or contact with environmental mycobacteria (Van Pinxteren et al. 2000).

Decreased IFN- $\gamma$ levels were observed in the $\mathrm{NC}$ and suspected TB disease groups after ESAT- 6 stimulation, compared to PPD stimulation. This shows that the response to ESAT-6 is of greater specificity, and that previous BCG vaccination may be interfering with specificity after PPD stimulation (Figure).

Based on the ESAT-6 antigen's higher specificity compared to the PPD antigen, the latent TB infection group's IFN- $\gamma$ production was significantly greater than the NC group's ( $<<0.0030$; Fig. A). This ability to develop such an early diagnostic for the detection of latent TB infection is very important for early treatment of this disease, especially in children.

Further studies are required to clarify the true value of this assay, particularly in children with suspected TB disease and children with latent TB infection (Marais \& Pai 2006).

TABLE

Characteristics of the groups

\begin{tabular}{|c|c|c|c|}
\hline Variable & Negative control $^{a}(\mathrm{n}=22)$ & Latent TB infection $^{a}(\mathrm{n}=16)$ & Suspected TB disease $1^{a, b}(\mathrm{n}=21)$ \\
\hline Age (years) Mean \pm SD & $9.7 \pm 2.4$ & $7.6 \pm 2.7$ & $10.2 \pm 3.0$ \\
\hline Male (\%) & $9(40.9)$ & $11(68.7)$ & $10(47.6)$ \\
\hline Female (\%) & $13(59.1)$ & $5(31.3)$ & $11(52.4)$ \\
\hline TST Mean \pm SD mm & 0 & $10 \pm 4.3$ & $14 \pm 6.7$ \\
\hline
\end{tabular}

$a$ : scar characteristics of BCG vaccination was observed in all children; $b$ : two children with extrapulmonary TB; $\mathrm{SD}=\mathrm{Standard}$ Deviation. 
A.

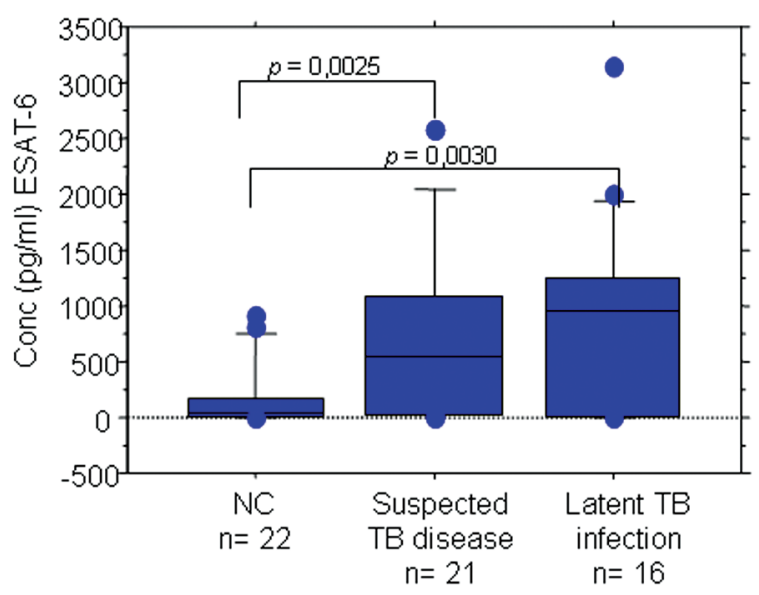

$\mathrm{B}$

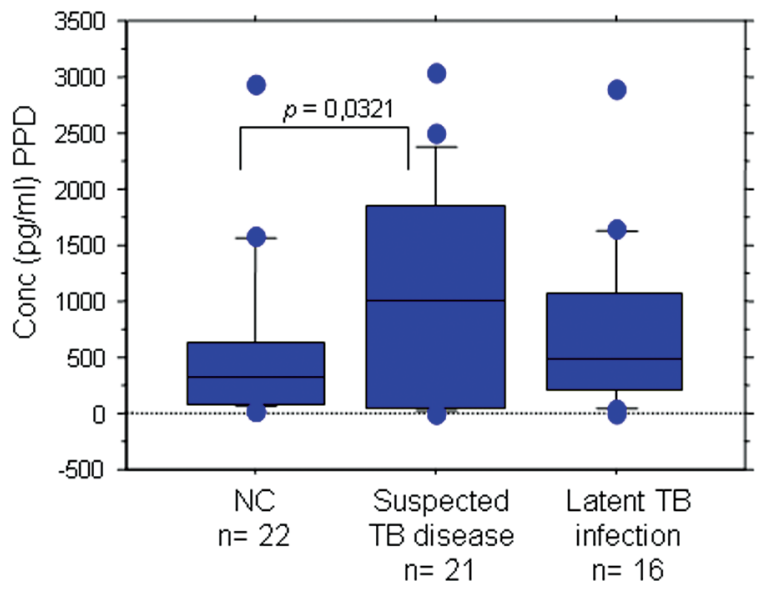

Box Plot quartiles and medians of IFN- $\gamma$ levels $(\mathrm{pg} / \mathrm{ml})$ to early secretory antigen target-6, ESAT-6 (A) and purified protein derivate, PPD (B) measured by Quantikine ELISA in supernatants of suspected TB disease patients $(n=21)$, latent TB infection $(n=16)$ and negative controls $(\mathrm{NC})(\mathrm{n}=22)$. Statistical differences were observed between $\mathrm{NC}$ and latent TB group $(\mathrm{p}=0.0030)$ and between NC and suspected TB disease patients $(p=0.0025)$ when stimulated with ESAT-6, and between NC and suspected TB disease patients $(p=0.0321)$ when the stimulus was PPD.

\section{ACKNOWLEDGEMENTS}

To all patients and control subjects for their cooperation.

\section{REFERENCES}

Aggerbeck H, Madsen SM 2006. Safety of ESAT-6. Tuberculosis 86: 363-373.

Arend SM, Van Meijgaarden KE, de Boer K, de Palou EC, Van Soolingen D, Ottenhoff TH, Van Dissel JT 2002. Tuberculin skin testing and in vitro T-cell responses to ESAT- 6 and culture filtrate protein 10 after infection with Mycobacterium marinum or Mycobacterium kansasii. J Infect Dis 186: 1797-1807.

ATS - American Thoracic Society 2000a. Diagnostic standards and classification of tuberculosis in adult and children. Am J Resp Crit Care Med 161: 1376-1395.

ATS - American Thoracic Society 2000b. Targeted tuberculin testing and treatment of latent tuberculosis infection. Morb Mortal Wkly Rep 49: 1-51.
Connel TG, Curtis N, Ranganathan SC, Buttery JP 2006. Performance of a whole blood interferon gamma assay for detecting latent infection with Mycobacterium tuberculosis in children. Thorax 61: 616-620.

Dohertty TM, Demissie A, Olobo J, Wolday D, Britton S, Eguale T, Ravn P, Andersen P 2002. Immune responses to the Mycobacterium tuberculosis-specific antigen ESAT-6 signal subclinical infection among contacts of tuberculosis patients. J Clin Microbiol 40: 704-706.

Goletti D, Vincenti D, Carrara S, Butera O, Bizzoni F, Bernardini G, Amicosante M, Girardi E 2005. Selected RD1 peptides for active tuberculosis diagnosis: comparison of a gamma interferon wholeblood enzyme-linked immunosorbent assay and an enzyme-linked immunospot assay. Clin Diagn Lab Immunol 12: 1311-1316.

Harboe M, Oettinger T, Wiker HG, Rosenkrands I, Andersen P 1996. Evidence of occurrence of the ESAT-6 protein in Mycobacterium tuberculosis and virulent Mycobacterium bovis and for its absence in Mycobacterium bovis BCG. Infect Immun 64: 16-22.

Hijjar MA, Oliveira MJPR, Teixeira GM 2001. A tuberculose no Brasil e no mundo. Bol Pneumol Sanit 9: 9-16.

Houwert KA, Borggreven PA, Schaaf HS, Nel E, Donald PR, Stolk J 1998. Prospective evaluation of World Health Organization criteria to assist diagnosis of tuberculosis in children. Eur Respir $J$ 11: $1116-1120$.

Jasmer RM, Nahid P, Hopewell PC 2002. Clinical practice. Latent tuberculosis infection. $N$ Engl J Med 347: 1860-1866.

Kunst H 2006. Diagnosis of latent tuberculosis infection: the potential role of new technologies. Respir Med 100: 2098-2106.

Lein AD, von Reyn CF, Ravn P, Horsburgh C Jr, Alexander LN, Andersen P 1999. Cellular immune responses to ESAT-6 discriminate between patients with pulmonary disease due to Mycobacterium avium complex and those with pulmonary disease due to Mycobacterium tuberculosis. Clin Diagn Lab Immunol 6: 606-609.

Marais BJ, Pai M 2007. Recent advances in the diagnosis of childhood tuberculosis. Arch Dis Child 92: 446-452.

Munk ME, Arend SM, Brock I, Ottenhoff TH, Andersen P 2001. Use of ESAT-6 and CFP-10 antigens for diagnosis of extrapulmonary tuberculosis. J Infect Dis 183: 175-176.

Pai M, Riley LW, Colford JM 2004. Interferon- $\gamma$ assays in the immunodiagnosis of tuberculosis: a systematic review. Lancet Infect Dis 4: 761-776.

Ravn PA, Demissie A, Eguale T, Wondwosson H, Lein D, Amoudy HA, Mustafa AS, Jansen AK, Holm A, Rosenkrands I, Oftung F, Olobo J, von Reyn F, Andersen P 1999. Human T cell responses to the ESAT-6 antigen from Mycobacterium tuberculosis. J Infect Dis 179: 637-645.

Ravn PA, Munk ME, Andersen AB, Lundgren B, Lundgren JD, Nielsen LN, Jensen AK, Andersen P, Weldingh K 2005. Prospective evaluation of a whole-blood test using Mycobacterium tuberculosisspecific antigens ESAT- 6 and CFP-10 for diagnosis active tuberculosis. Clin Diagn Lab Immunol 12: 491-496.

Sant'Anna CC, Mourgues LV, Ferrero F, Balanzar AM 2002. Diagnóstico e terapêutica da tuberculose infantil - uma visão atualizada de um antigo problema. J Pediatr (Rio J) 78: 205-214.

Scarpellinni P, Tasca S, Galli L, Beretta A, Lazzarin A, Fortis C 2004. Selected pool of peptides from ESAT- 6 and CFP-10 proteins for detection of Mycobacterium tuberculosis infection. J Clin Microbiol 42: 3469-3474.

Teixeira HC, Abramo C, Munk ME 2007. Diagnóstico imunológico 
da tuberculose: problemas e estratégias para o sucesso. $J$ Bras Pneumol 33: 323-334.

Tufariello JM, Chan J, Flynn JL 2003. Latent tuberculosis: mechanisms of host and bacillus that contribute to persistent infection. Lancet Infect Dis 3: 578-590.

Van Pinxteren LAH, Ravn P, Agger EM, Pollock J, Andersen P 2000. Diagnosis of tuberculosis based on the two specific antigens ESAT-6 and CFP-10. Clin Diagn Lab Immunol 7: 155-160.
VendraminiSHF, Gazetta CE, Chiaravalotti Netto F, Cury MR, Meirelles EB, Kuyumjian FG, Villa TCS 2005. Tuberculose em município de porte médio do Sudeste do Brasil: indicadores de morbidade e mortalidade de 1985 a 2003. J Bras Pneumol 31: 237-243.

Weldingh K, Rosenkrands I, Okkels LM, Doherty TM, Andersen P 2005. Assessing the serodiagnostic potential of 35 Mycobacterium tuberculosis proteins and identification or four novel serologic antigens. J Clin Microbiol 43: 57-65. 